\title{
EVALUATION OF THYROID DYSFUNCTION IN ADULT PATIENTS OF CELIAC
} DISEASE

\author{
Nauman Wazir ${ }^{1}$, Shafqat-Ur-Rehman ${ }^{2}$
}

\section{ABSTRACT:}

\section{OBJECTIVES:}

To assess free thyroxine (fT4), thyroid stimulating hormone (TSH), and anti thyroid peroxidase antibodies (anti TPO abs) in adult Celiac disease patients and non-celiac controls and to find out any statistically significant difference in their corresponding means between the two groups.

\section{METHODOLOGY:}

The study design was analytical cross sectional. Sixty adult patients of celiac disease (CD) and 30 apparently healthy non-celiac adults were included in the study. CD patients had earlier been diagnosed by elevated levels of serological evidence of elevated (greater than 15X ULN) anti tissue transglutaminase (TTG) (IgA class) antibodies. CD was ruled out in the control group by normal levels of the antibodies. TSH, FT4 and anti TPO abs were obtained from all individuals of CD patient and control groups.

\section{RESULTS:}

Mean age of Celiac disease in patients was $23.85 \pm 5.43$ years. Mean age of individuals in the control group was $24.26 \pm 5.55$ years. Statistically significant difference in mean TSH and anti-TPO abs levels between the CD patient group and control group ( $p$ values of 0.03 and 0.038 , respectively) was present. No statistically significant difference was seen between mean fT4 of patients and control group $(p=0.74)$. Subclinical and overt hypothyroidism was present in $10 \%$ and $5 \%$ of $C D$ patients, while anti TPO abs was positive in $16.6 \%$ of CD patients.

\section{CONCLUSION:}

There is a considerably high prevalence of subclinical and overt hypothyroidism as well as serological evidence of thyroid dysfunction in adult patients of $C D$.

KEYWORDS: Celiac Disease, Thyroid Stimulating Hormone, Anti Thyroid Peroxidase Antibodies

How to cite this article:

Wazir N, Rehman SU. Evaluation of Thyroid Dysfunction in Adult Patients of Celiac Disease. J Gandhara Med Dent Sci.

2021;8(4): $3-8$

https://doi.org/10.37762/jgmds.8-4.248

\section{Correspondence}

${ }^{1}$ Nauman Wazir, Assistant Professor, Department of

Medicine, Lady Reading Hospital, Peshawar

Contact: +92-336-9190857.

Email. Nuaman.wazir@yahoo.com

${ }^{2}$ Assistant Professor, Department of Medicine, Naseer

Teaching hospital, Peshawar Complex. Peshawar

\section{INTRODUCTION:}

Celiac disease (CD), which is an immunemediated enteropathy, develops in genetically susceptible individuals upon consumption of gluten containing $\operatorname{diet}^{1}$. The CD is characterized by gastrointestinal symptoms and malabsorption resulting from macroscopic 
and microscopic changes in the small bowel mucosa along with a wide range of extraintestinal manifestations ${ }^{2}$. It is shown to be related to human leukocyte antigen (HLA) genotypes (DQ2 and DQ8) $)^{3,4}$. The prevalence of $C D$ had been reported as about $1 \%$ in the general population in Europe ${ }^{5,6}$. There is sufficient evidence of a strong association between $C D$ and several immune mediated diseases such as type-1 diabetes mellitus, autoimmune thyroid disease, Sjogren's syndrome, Down, Addison, Turner and syndromes, primary biliary cirrhosis, autoimmune adrenal failure and inflammatory bowel diseases ${ }^{7,8}$. Among these, autoimmune thyroid disease is a common autoimmune disorder whose prevalence is $10-12 \%$ in the general population worldwide ${ }^{9}$. The association of celiac disease with autoimmune thyroid disease was first described around three decades ago ${ }^{10}$.

The exact pathogenesis of co-existence of autoimmune thyroid disease and $C D$ is not known $^{11}$, though epidemiological studies point towards a common genetic background for these autoimmune T-cell mediated diseases $^{12,13}$. Numerous studies have shown a higher prevalence of thyroid disease (TD) in individuals with $C D$ as compared to the general population ${ }^{14,15}$. In a study, TD was three times higher in untreated adults with celiac disease, while it's prevalence in children with CD was $26.2 \%{ }^{16}$. Similarly, a study reported its prevalence to be $10.8 \%{ }^{17}$, and children with celiac disease had a higher prevalence of thyroid disease ${ }^{18}$. Meloni et al, ${ }^{19}$ showed a strong association of TD with $\mathrm{CD}$ in Sardinian children, where its prevalence was $10.5 \%$. In an Irish study the prevalence of TD in adults with CD was $7 \%{ }^{20}$. Toumi et al, ${ }^{21}$ while evaluating the frequency of anti-thyroid antibodies in a Tunisian study, reported the frequency of TD in CD patients to be $8.3 \%$. In another study the prevalence of $C D$ in patients with TD was reported to be $2 \%^{22}$. It has also been shown that the prevalence of TD in patients with $C D$ has increased, therefore suggesting that $C D$ patients should be screened for $T D^{19}$. A study found statistically significant differences between Thyroid Stimulating Hormone (TSH) levels and Anti Thyroid Peroxidase antibody level (Anti TPO) between paediatric patients of CD and controls ${ }^{18}$. If left untreated, TD can result in marked increase in morbidity in $C D^{17}$. Taking into consideration the previously established associations between TD and CD, and the significance of TD treatment in CD patients, and the fact that, to the best of our knowledge, no studies have been carried out in Pakistan on screening the prevalence of TD in adult $C D$ patients, this study was aimed to assess free thyroxine (fT4), TSH, and TPO antibody in adult $C D$ patients and non-celiac controls to find out whether there is any statistically significant difference in their corresponding means between the two groups.

\section{METHODOLOGY:}

This was an analytical cross-sectional study. Sixty patients of $C D$ and 30 non-celiac healthy controls were included in the study. The study was performed at the Department of Medicine, Naseer Teaching Hospital, Peshawar. The CD group was selected from the Department of Medicine at Naseer Teaching Hospital, Peshawar, and from the Centre of Gastroenterology and Hepatology, Peshawar. Control group was selected from healthy staff members and apparently healthy attendants of hospitalized patients. The inclusion criteria of both $C D$ and control groups were age $>16$ years and either sex, whereas additional inclusion criterion for $C D$ group was elevated levels (>15X ULN) of serum anti tissue transglutaminase (IgA class) antibodies. A further inclusion criterion in the control group was normal levels of serum anti tissue transglutaminase (IgA class) antibodies. Thyroid function test including free thyroxine (fT4) and thyroid stimulating hormone (TSH) were performed in both cases and control groups utilizing Vitros ECIQ immunodiagnostic system; to measure TSH, 
TSH kit by Ortho-Clinical Diagnostics was utilized (Reference range: 0.4-4.2 mIU/L) and for fT4 measurement, kit by Ortho-Clinical Diagnostics was utilized (Reference range: 10-30 pmol/L). Anti TPO were also measured by manual ELISA technique to measure antiTPO, Anti-TPO Elisa kit by Eskulisa was used (Levels $>60 \mathrm{IU} / \mathrm{mL}$ were taken as positive). The data was analysed by using standard SPSS software version 23. Mean \pm SD was calculated for quantitative variables like age, TSH, FT4 and anti TPO. Percentages and frequency were calculated for qualitative variables. Analysis was done by t-test to determine group mean differences. A value for $p$-value $<0.05$ was considered statistically significant.

\section{RESULTS:}

A total of $60 \mathrm{CD}$ patients and 30 non-CD healthy controls were included in the study. Among patients, 39 (65\%) were female and $21(35 \%)$ were male, while $15(50 \%)$ were male and $15(50 \%)$ were females in the control group. Mean age of celiac disease in patients was $23.85 \pm 5.43$ years. Mean age of individuals in the control group was $24.26 \pm 5.55$ years. Family history of thyroid dysfunction and CD was present in $3(5 \%)$ and $1(3.3 \%)$ in the patient group, respectively. Five $(8.33 \%)$ CD patients were known to have type-1 diabetes mellitus and were compliant with insulin therapy.

Mean TSH levels were $3.32 \pm 2.5 \mathrm{mU} / \mathrm{L}$ in the CD patient group and $2.29 \pm 0.74 \mathrm{mU} / \mathrm{L}$ in the control group. There was a statistically significant difference between mean TSH levels $(p=0.03)$ of $C D$ patients and that of controls. Nine (15\%) CD patients had elevated TSH levels, with $6(10 \%)$ CD patients having subclinical hypothyroidism (normal fT4 levels) and 3 (5\%) having overt hypothyroidism (low fT4 levels). All the individuals in the control group had normal $\mathrm{TSH}$ levels. There was no statistically significant difference between the mean fT4 levels of the two groups $(p=0.76)$. Ten
(16.6\%) of CD patients had positive anti TPO abs while they were positive in only 1 individual of the control group. The difference between the mean TPO values of the two groups was statistically significant $(p=0.038)$. The TSH, fT4 and anti TPO levels of CD patient group and control groups are shown in Table 1.

Table 1: Mean and SD of TSH, fT4 and Anti TPO Abs of CD Patients and Control Groups

\begin{tabular}{|c|c|c|c|}
\hline Parameter & $\begin{array}{c}\text { CD } \\
\text { Patients }\end{array}$ & Controls & P-Value \\
\hline $\mathrm{TSH}$ & $\begin{array}{c}3.32 \pm 2.5 \\
\mathrm{mU} / \mathrm{L}\end{array}$ & $\begin{array}{c}2.29 \pm 0.74 \\
\mathrm{mU} / \mathrm{L}\end{array}$ & 0.03 \\
\hline fT4 & $\begin{array}{c}17.82 \pm 3.8 \\
1 \mathrm{pmol} / \mathrm{L}\end{array}$ & $\begin{array}{c}19.04 \pm 2.35 \\
\mathrm{pmol} / \mathrm{L}\end{array}$ & 0.74 \\
\hline Anti TPO & $\begin{array}{c}22.21 \pm 21 \\
37 \mathrm{IU} / \mathrm{ml}\end{array}$ & $\begin{array}{c}13.54 \pm 10.02 \\
\mathrm{IU} / \mathrm{ml}\end{array}$ & 0.038 \\
\hline
\end{tabular}

\section{DISCUSSION:}

Various previous studies had reported an association between $C D$ and other autoimmune diseases, especially thyroidal diseases $3,11,12,17,22$. This study attempted to analyse differences of thyroid function tests (TSH and fT4) and anti TPO abs between the adult $C D$ patients and healthy controls. The results revealed that the difference of TSH and anti TPO abs was statistically significant between the two groups. However, there was no statistically significant difference of fT4 levels between the groups. In this study, thyroid disease was diagnosed in $9(15 \%)$ of CD patients and none in the control group. Six $(10 \%) \quad C D$ patients had subclinical hypothyroidism, whereas overt hypothyroidism was present in $3(5 \%)$ CD patients. A study conducted on adult celiac patients for thyroid dysfunction, reported similar results ${ }^{23}$. They showed that all $C D$ patients remained euthyroid, only $8.6 \%$ showed mild elevation in serum TSH levels. Similarly another study conducted on patients showed $10.1 \%$ subclinical and $3.8 \%$ overt hypothyroidism in their study population ${ }^{24}$. A researcher recruited $241 \mathrm{CD}$ patients and 
reported $12.03 \%$ subclinical and $0.8 \%$ overt hypothyroidism $^{25}$. In a study hypothyroidism was diagnosed in $12.9 \%$ of CD patients ${ }^{22}$. A researcher investigated the risk of thyroid disease in the Swedish population with $C D$ and established that $C D$ was associated with hypothyroidism (hazard ratio $=4.4)^{25}$. Similarly, a study found an increased prevalence of thyroid dysfunction (hypothyroidism 19.2\% and hypothyroidism $21.2 \%$ ) in CD patients ${ }^{26}$. In the study the prevalence of hypothyroidism in patients with $C D$ was significantly increased compared to that in the control group ${ }^{25}$. The association between $\mathrm{CD}$ and TD can be explained by the presence of shared genetic factors and may justify the increased prevalence of autoimmune diseases seen in $\mathrm{CD}^{4}$. Human HLAs (DQ2 and DQ8) have been shown to be common in thyroid disease and $C D$, and patients who have overlapping disease are mostly HLA DQ2 positive ${ }^{23}$. The difference in percentage of subclinical and overt hypothyroidism in our study and some of the above cited studies could be explained by differences in the ethnic background and age of the CD patients.

This study showed anti TPO antibodies to be positive in $10(16.6 \%)$ CD patients and in only one control. In the study by anti TPO abs were positive in $16.4 \%$ of the paediatric patients of $C D^{26}$. Our results regarding anti TPO abs positivity in CD patients are quite consistent with the results of the cited studies. This study also showed that anti TPO positivity was correlated with thyroid dysfunction in CD patients; TSH was elevated in $9(15 \%)$ CD patients whereas anti TPO abs were positive in $10(16.6 \%)$ CD patients.

\section{CONCLUSION:}

The results of this study show a high prevalence (10\%) of subclinical hypothyroidism (normal fT4, raised serum TSH levels) and notable prevalence $(5 \%)$ of overt hypothyroidism (low fT4, low TSH) in adult patients with $\mathrm{CD}$. The prevalence of anti TPO abs positivity was also high $(16.6 \%)$ in adult CD patients. Overall, there was a statistically significant difference between mean TSH and anti TPO abs levels in CD and control groups. As supported by the results of this study and previous other studies, it is recommended to perform thyroid function tests in all patients of celiac disease, and those with subclinical hypothyroidism should be followed as per the published guidelines.

CONFLICT OF INTEREST: None

FUNDING SOURCES: None

\section{REFERENCES :}

1. Caio G, Volta U, Sapone A, Leffler DA, De Giorgio R, Catassi C, et al. Celiac disease: a comprehensive current review. BMC Med. 2019;17(1):1-20.

2. Horwitz $A$, Skaaby $T$, Kårhus LL, Schwarz P, Jørgensen T, Rumessen JJ, et al. Screening for celiac disease in Danish adults. Scand J Gastroenterol. 2015;50:824-31.

3. Castro PD, Harkin G, Hussey M, Christopher B, Kiat C, Chin JL, et al. Changes in presentation of celiac disease in Ireland from the 1960s to 2015. Clin Gastroenterol Hepatol. 2017;15(6):864-71.

4. Parzanese I, Qehajaj D, Patrinicola F, Aralica M, Chiriva-Internati M, Stifter $S$, et al. Celiac disease: from pathophysiology to treatment. World J Gastrointest Pathophysiol. 2017;8(2):27.

5. Moradniani M, Sabzevari ZM, Aaliehpour A, Baharvand $P$. Demographic features and high prevalence of celiac disease in patients with irritable bowel syndrome in Khoram Abad, Lorestan. Govaresh. 2017;22:195201.

6. Singh P, Arora A, Strand TA, Leffler DA, Catassi C, Green PH, et al. Global prevalence of celiac disease: 
systematic review and meta analysis.

Clin Gastroenterol Hepatol. 2018;16(6):823-36.

7. Kahaly GJ, Frommer L, Schuppan D. Celiac disease and endocrine autoimmunity-the genetic link. Autoimmun Rev. 2018;17(12):116975.

8. Bibbò $S$, Pes GM, Usai-Satta P, Salis $\mathrm{R}$, Soro S, Colosso BM, et al. Chronic autoimmune disorders are increased in coeliac disease: a case-control study. Medicine. 2017;96(47).

9. Al-Shahrani AS, El-Metwally A, AlSurimi K, Salih SB, Saleh Y, AI-Shehri $A$, et al. The epidemiology of thyroid diseases in the Arab world: a systematic review. J Public Health Epidemiol. 2016;8(2):17-26.

10. Ponzo V, Ferrocino I, Goitre I, Pellegrini $M$, Bruno $M$, Astegiano $M$, et al. Non-celiac gluten/wheat sensitivity: clinical characteristics and microbiota and mycobiota composition by response to the gluten challenge test. Nutrients. 2021;13(4):1260.

11. Roy A, Laszkowska M, Sundström J, Lebwohl B, Green PH, Kämpe O, et al. Prevalence of celiac disease in patients with autoimmune thyroid disease: a meta-analysis. Thyroid. 2016;26(7):880-90.

12. Abadie V, Kim SM, Lejeune $T$, Palanski BA, Ernest JD, Tastet $O$, et al. IL-15, gluten and HLA-DQ8 drive tissue destruction in coeliac disease. Nature. 2020;578(7796):600-4.

13. Nishi M. Diabetes mellitus and thyroid diseases. Diabetol Int. 2018;9(2):10812.

14. Baharvand $\mathrm{P}$, Hormozi M, Aaliehpour A. Comparison of thyroid disease prevalence in patients with celiac disease and controls. Gastroenterol Hepatol Bed Bench. 2020;13(1):44-9.

15. Kurien M, Mollazadegan K, Sanders DS, Ludvigsson JF. Celiac disease increases risk of thyroid disease in patients with type 1 diabetes: a nationwide cohort study. Diabetes Care. 2016;39(3):371-5.

16. Roberta M, Federica G, Stefano K, Francesco DM, Fabiola F, Gioacchino $\mathrm{L}$, et al. Thyroid and celiac disease in pediatric age: a literature review. Acta Bio Medica: Atenei Parmensis. 2018;89(Suppl 9):11.

17. Sun $X$, Lu L, Yang R, Li YB, Shan L, Wang $Y$. Increased incidence of thyroid disease in patients with celiac disease: a systematic review and meta-analysis. PLOS

One. 2016;11:e0168708.

18. Norström $F$, Van-Der-Pals $M$, Myléus A, Hammarroth $S$, Högberg L, Isaksson A, et al. Impact of thyroid autoimmunity on thyroid function in 12-year-old children with celiac disease. J Pediatr Gastroenterol Nutr. 2018;67(1):64-8.

19. Lerner A, Shoenfeld $\mathrm{Y}$, Matthias $\mathrm{T}$. Adverse effects of gluten ingestion and advantages of gluten withdrawal in nonceliac autoimmune disease. Nutr Rev. 2017;75(12):1046-58.

20. Shah A, Walker M, Burger D, Martin $\mathrm{N}$, Von Wulffen M, Koloski N, et al. Link between celiac disease and inflammatory bowel disease. J Clin Gastroenterol. 2019;53(7):514-22.

21. Larson SA, Khaleghi S, Rubio-Tapia A, Ovsyannikova IG, King KS, Larson $\mathrm{JJ}$, et al. Prevalence and morbidity of undiagnosed celiac disease from a community-based study. Gastroenterology. 2017;152(4):830-9.

22. Hormozi M, Aaliehpour A. Comparison of thyroid disease prevalence in patients with celiac disease and controls. Gastroenterol Hepatol Bed Bench. 2019.

23. Gupta V, Singh A, Khadgawat R, Agarwal A, lqbal A, Mehtab W, et al. The spectrum of clinical and subclinical endocrinopathies in 
treatment-naïve patients with celiac disease. Indian J Gastroenterol. 2019;38(6):518-26.

24. Trovato CM, Raucci U, Valitutti $F$, Montuori M, Villa MP, Cucchiara S, et al. Neuropsychiatric manifestations in celiac disease. Epilepsy Behav. 2019;99:106393.

25. Lerner A, Matthias T. Autoimmune thyroid diseases in celiac disease: if and when to screen. Int $\mathrm{J}$ Celiac Dis. 2016;4:124-6.

26. Myléus A, Reilly NR, Green PH. Rate, risk factors, and outcomes of nonadherence in pediatric patients with celiac disease: a systematic review. Clin Gastroenterol Hepatol. 2020;18(3):562-73.

\section{CONTRIBUTORS}

1. Nauman Wazir - Concept \& Design; Data Analysis/Interpretation; Drafting Manuscript; Final Approval

2. Shafqat-Ur-Rehman - Data Acquisition; Critical Revision; Supervision; Final Approval 